\title{
UNA POÉTICA PERIODÍSTICA: PAISAJES SENTIMENTALES DEL PRESENTE EN TEORÍA DE LA GRAVEDAD, DE LEILA GUERRIERO
}

\author{
Virginia P. Forace
}

Centro de Letras Hispanoamericanas (CELEHIS)

Instituto de Humanidades y Ciencias Sociales (INHUS)

Universidad Nacional de Mar del Plata

Argentina

virginiaforace@gmail.com

ORCID: 0000-0002-I488-0702

Fecha de recepción: 08/03/202 I | Fecha de aceptación: 29/06/202 I

Resumen: Teoría de la gravedad (2019) es un libro que reúne las columnas de Leila Guerriero publicadas en El País (España) entre 2014 y 2019. Por el contenido temático (la pérdida, el amor, el miedo, la muerte, la escritura) y la estrategia narrativa (escritas en primera persona, con un tono en apariencia personal e intimista), se las ubica en las tendencias que se conocen como giro subjetivo y giro afectivo. Se propone que no se trata de una colección de "crónicas íntimas", sino de la presentación de una poética periodística que busca salir de los espacios habituales de la tragedia o lo marginal e indagar sobre otras zonas de la existencia, para deconstruir los territorios afectivos y las interdicciones emocionales del presente. Se delinean dos zonas textuales del libro para el análisis: una, en la que predomina la rememoración de la experiencia vital y la ficción de un yo referencial; otra, la de las microficciones tituladas "Instrucciones" y las reflexiones de corte sentimental, en las que se anula esa ilusión referencial propia de las escrituras del yo.

Palabras clave:Argentina; siglo XXI; crónica; Leila Guerriero; Teoría de la gravedad.

\section{A journalistic poetics: sentimental landscapes of the present in Leila Guerriero's Teoría de la gravedad}

Abstract: The volume Teoría de la gravedad (2019) is a collection of columns by Leila Guerriero published in the Spanish newspaper El País between 2014 and 2019. Their thematic content (loss, love, fear, death, writing) and narrative strategy (first person and intimate), situates them in the subjective turn and affective turn movements. Rather 
than a collection of "intimate chronicles", they present journalistic poetics that seek to abandon the usual confines of tragedy or the marginal and probe other areas of existence to deconstruct affective domains and emotional interdictions of the present. Two topics areanalyzed: one dominated by the recollection of life experience and the fiction of a referential self, and the other, made up of microfictions entitled "Instructions" and sentimental reflections in which that referential illusion, typical of the writings of the self, disappears.

Keywords: Argentina; XXI century; chronicle; Leila Guerriero; Teoría de la gravedad.

\title{
Uma poética jornalística: paisagens sentimentais do presente em Teoría de la gravedad, de Leila Guerriero
}

\begin{abstract}
Resumo: Teoría de la gravedad (2019) é uma coletânea das colunas de Leila Guerriero publicadas no El País (Espanha) entre 2014 e 2019. Pelo conteúdo temático (perda, amor, medo, morte, escrita) e as estratégias narrativas (escritas em primeira pessoa, em um tom aparentemente pessoal e íntimo), os textos se situam nas tendências conhecidas como giro subjetivo e giro afetivo. Sustentamos, no entanto, que não se trata de uma coletânea de "crônicas íntimas", mas sim da apresentação de uma poética jornalística que busca sair dos espaços usuais da tragédia ou do marginal, e indagar sobre outras áreas da existência, para desconstruir os territórios afetivos e interdições emocionais do presente. Duas áreas textuais do livro são delineadas na análise: na primeira predominam a lembrança da experiência de vida e a ficção de um self referencial; na segunda - onde aparecem as microficções intituladas "Instruções" e as reflexões de carácter sentimental-, se anula aquela ilusão referencial típica das escritas de si.
\end{abstract}

Palavras-chave:Argentina; Século XXI; crônica; Leila Guerriero; Teoría de la gravedad.

\section{El lado "A" de lo real}

Vengo aquí. Saqueo mi vida. Ahí la tienen. ¿Para qué la quieren? Yo, a veces, la prendería fuego.

Leila Guerriero, "El pacto", Teoría de la gravedad.

1 laconismo de este epígrafe manifiesta una notable consciencia
escrituraria, no solo por la cadencia sumaria que enhebra las fra-
ses, sino por la concisión alcanzada en esta imagen del desacuerdo entre un otro que busca conocer al yo y una subjetividad que desaira esas aspiraciones al ofrecerse con absoluta irreverencia. Este fragmento de "El pacto" contrasta con la larga enumeración que lo precede, una treintena de líneas en las cuales una primera persona se autodefine por extensión, por acumulación y, sobre todo, por contradicción: "la muy sincera, la muy falsa, la esquiva, la insensible, la mísera, la idiota, la astuta, la excesiva, la austera, la retrógrada, la feminista, la jurásica, la iracunda, la violenta, la agresiva, la suave, la tan suave, aquí yo, yo, yo" (Guerriero Teoría de la gravedad 5). Así inicia el primer texto 
del último libro de Leila Guerriero, como un objeto arrojado a gran velocidad contra los lectores desprevenidos, una colisión que nos indica en pocas líneas una poética completa: la dinámica oscilante entre la concisión y la expansión, y el yo que rehúye a mostrarse, a volverse materia de escritura ${ }^{1}$.

Teoría de la gravedad (2019) reúne casi una centena de textos publicados en El País (España) entre 2014 y 2019. Su colaboración con ese medio había iniciado en 2006 con algunos reportajes y desde 2014 mantuvo una prolífica y ecléctica columna de opinión semanal ${ }^{2}$. De los numerosos aportes de esos ańos, para elaborar este libro Guerriero seleccionó solo aquellos textos redactados en primera persona y que discurrían por temas como la pérdida, el amor, el miedo, la muerte, la escritura, todos con un tono en apariencia personal e intimista. Es así que la constitución de este volumen manifiesta una intención compositiva que busca eliminar los elementos coyunturales que aparecían en las columnas para concentrarse en las reflexiones de una subjetividad.

Es indudable que vivimos una época marcada por la preeminencia de la dimensión subjetiva y por la tematización del afecto (el giro afectivo); las narraciones contemporáneas exploran lo íntimo, lo personal y lo cotidiano y lo convierten en materiales narrativos con un lugar notable en el espacio público ${ }^{3}$. De esta forma, a diferencia de algunas orientaciones críticas que postulan la existencia de una "crónica íntima” o "crónica de la cotidianeidad" (Gorodischer) ${ }^{4}$, la indaga-

1 Leila Guerriero (Junín, 1967) es periodista y editora. Ha publicado Los suicidas del fin del mundo. Crónica de un pueblo patagónico (Tusquets, 2005), Frutos extraños. Crónicas reunidas 2001-2008 (Taurus, 2009), Plano americano (Ediciones UDP, 2013), Una historia sencilla (Anagrama, 2013), Zona de obras (Círculo de Tiza, 2014), Opus Gelber. Retrato de un pianista (Ediciones UDP/Anagrama, 2019), Teoría de la gravedad (Libros del Asteroide, 2019) y La otra guerra. Una historia del cementerio argentino en las islas Malvinas (Anagrama, 2021). Como editora o compiladora, también se cuentan Los malditos (Ediciones UDP, 2011), Los malos (Ediciones UDP, 2015), Un mundo lleno de futuro. Diez crónicas de América Latina (Planeta, 2017), Voltios. La crisis energética y la deuda eléctrica (Planeta, 2017), Cuba en la encrucijada (Debate, 2017) y Extremas (Ediciones UDP, 2019).

2 Cuando inició con las columnas, anunciaba: "Estaré aquí un tiempo, hablando, hablándoles. ¿De qué? Del tamaño de la aridez de nuestros corazones. De repollos y reyes y de por qué el mar hierve y de si los cerdos tienen alas. Del horror del amor cuando termina. De todas las cosas que estaban hechas para olvidar que no hemos olvidado nunca; de las que estaban hechas para no olvidar jamás (el dolor, los muertos queridos, aquella tarde en la arena) y que, sin embargo, hemos olvidado para siempre" (Guerriero "Aquí estaré").

3 Leonor Arfuch ("El giro afectivo") señala que el giro afectivo (the affective turn) ganó espacio en la reflexión de las ciencias sociales en sintonía con ciertos cambios sociales y políticos en las sociedades contemporáneas. Estas modificaciones elaboraron una esfera pública emocional -con la distinción normativa entre emociones tóxicas y saludables- y una variedad de registros de lo afectivo. Los estudios teóricos sobre las emociones son variados, desde aquellos relacionados con los estudios norteamericanos, influidos por la teoría queer, pasando por la historia de las emociones, herederos de la historia cultural, hasta la teoría de las emociones en la filosofía política y en la teoría del sujeto.

4 Julián Gorodischer afirma que entre los años 2000 y 2017 el periodismo narrativo argentino "ensanchó" los límites de su objeto y su método y desarrolló gran interés en las materias de la intimidad y la vida cotidiana (9). Esta tesis parece reduccionista si consideramos que esta "voz 
ción sobre la experiencia vivencial del "yo" narrador que realiza Guerriero en sus textos debería ubicarse en la serie literaria y cultural más amplia y en lo que se conoce como giro subjetivo (Sarlo Tiempo pasado) 5 . No se trata de una transformación en las crónicas en tanto género, sino en el sensorium actual en general.

Asimismo, en el caso de Guerriero, no es la primera vez que ella examina la zona de la intimidad en sus textos. Como ha analizado Mariana Bonano respecto de Frutos extraños (2009) -otra antología de crónicas publicadas originalmente en diversos medios impresos y digitales-, allí también la periodista había seleccionado textos en los cuales una voz intimista y un tono confesional predominaban y en los que se sondeaban aspectos concernientes a su identidad femenina y al cuestionamiento de los roles y mandatos establecidos. El espacio metadiscursivo construido en la sección "Discusiones" le servía para reflexionar sobre su práctica escrituraria y su posición de periodista/narradora ${ }^{6}$.

Sin embargo, mientras en esas crónicas el sujeto reivindicaba su diferencia y deconstruía con fina ironía y un poco de humor los mandatos sociales relacionados con lo femenino -especialmente en lo concerniente al campo de lo que podríamos llamar la cultura sentimental patriarcal y la figura de la mujer-, en Teoría de la gravedad lo personal y lo íntimo se recuperan para reflexionar sobre la "experiencia humana" en general (Guerriero "Quiero que mis columnas" $\mathrm{s} / \mathrm{p}$ ). Sería un error, entonces, pensar que se trata solo de una colección de "crónicas intimas" que perfilan para el lector a la propia Guerriero; por el contrario, lo que se produce en estos textos es la indagación acerca de otra zona de lo real a partir de una constelación de rememoraciones y anécdotas.

Casi una década antes de la publicación de estas columnas, en el texto "Sobre algunas mentiras del periodismo latinoamericano", la autora ya había sugerido que la crónica tenía mucho más que explorar que lo freak, lo marginal, lo pobre o lo violento, aunque habitualmente recayera en esos temas. Guerriero explicaba que esta paradoja respondía a una confusión naturalizada: creer que el periodismo de investigación o de denuncia es el único posible, como si esta orientación

intimista" no es una novedad; María Angulo Egea la ha identificado como una de las orientaciones que caracterizó el nuevo periodismo norteamericano y lo ha relacionado con un fenómeno de la época contemporánea y, en el caso argentino, puede hallarse en algunas crónicas de Sara Gallardo y María Moreno mucho antes del supuesto periodo de "ensanchamiento".

5 El giro subjetivo -en el espacio de los estudios literarios, también llamado "giro autobiográfico" (Giordano El giro autobiográfico), "giro intimista" (Link), "retorno del sujeto" (Arfuch El espacio biográfico), o "era de la intimidad" (Catelli)- hace referencia a la reubicación de la categoría de sujeto en el centro de las formas para comprender la relación con el mundo: "la indistinción entre espacios públicos y privados y el repliegue en lo privado; la afirmación ontológica de la diferencia a través de la multiplicación de las identidades -y el consecuente replanteo teórico de las mismas, en el sentido de un antiesencialismo-; el afianzamiento del neoliberalismo y por ende, del individualismo a ultranza, la competitividad feroz y el emprendedor de su propio destino como modelo social o asocial" (Arfuch "El giro afectivo" 247).

6 Este tono íntimo y autorreflexivo sobre su práctica también había aparecido en algunos textos compilados en Zona de Obras, como "Salvame" (escrito en 2011), "Listas" (2012), "Leer para escribir" (2012), "Aterrador" (2011), entre otros. 
equivaliera a una forma de "justicia", cuando en realidad lo único que hace la prensa es contar historias (Zona de Obras 101). Este error, confirmado por el circuito de legitimación de los premios, conllevaba un déficit a la hora de contar historias que "no rimen con catástrofe y tragedia" (Zona de Obras 101), y una sensación de culpa y vergüenza entre editores y escritores si ponían el foco en historias más "amables". En ese momento, con una certera lectura de la práctica del periodismo narrativo, Guerriero concluía: "Es probable, entonces, que la crónica latinoamericana no esté contando la realidad completa, sino siempre el mismo lado B: el costado que es la tragedia" (102).

¿Cuál es el "lado A" que faltaba contar? ¿Se pueden narrar historias cotidianas y humanas sobre los temores y dudas existenciales del presente en un medio masivo de comunicación sin ser etiquetado peyorativamente como "intimista"? ¿Es posible que la recuperación de la experiencia vital de un sujeto individual sirva como coartada para desarrollar aspectos más universales sobre la vida humana? La máxima escrituraria que había enunciado tantos años antes: escribir "Para entender, sí, hasta que duela"(111), sigue guiando la mirada de Guerriero en este volumen pero, en vez de volverse esa observadora invisible que caracteriza sus crónicas de investigación y sus perfiles, en estos textos el yo se hace protagonista y el movimiento de estos entrenados ojos pendulan de sí misma hacia el exterior.

En las páginas que siguen, me propongo analizar dos zonas textuales en Teoría de la gravedad: una, en la que predominan la rememoración de la experiencia vital y la ficción de un yo referencial; otra, la de las microficciones tituladas "Instrucciones" y las reflexiones de corte sentimental, en las que se anula esa ilusión referencial propia de las escrituras del yo y se deconstruyen los territorios y sujeciones afectivas y las interdicciones emocionales del presente.

\section{Hacia una reflexión de la experiencia humana}

Es cierto: es arduo encontrar interés en cosas que tenemos cerca. Y más cierto aún es que no todas las cosas que tenemos cerca son interesantes. Pero, si no estamos atentos, desaparecerán, ante nuestros ojos bien cerrados, mundos enteros.

Leila Guerriero, "Tenemos que hablar de Petty", Zona de obras.

Teoría de la gravedad, tanto por los temas abordados como por su composición en primera persona, parece orientarse hacia el mundo interior de una subjetividad: sus emociones y preocupaciones, los momentos de desesperación y los de felicidad tranquila, los aspectos prosaicos y cotidianos, los recuerdos personales -sobre la infancia, la adolescencia y las relaciones familiares y amorosas-, los afectos perdidos y encontrados. Toda esta constelación de escenas de 
la intimidad construye un espacio escriturario para aprehender la experiencia vital. Guerriero nos muestra que es necesario revisar lo que se ha experimentado, interpelarlo, sujetarlo por medio de la palabra para así poder asimilarlo, para comprenderlo, para que la vida no discurra mecánicamente.

$\mathrm{El}$ andamiaje que sostiene este propósito indagatorio se apoya en una mirada que funciona como un lente de aumento, que enfoca sucesos y objetos y sostiene la observación hasta el estrabismo o hasta que la luz que atraviesa esa lupa los abrasa. Porque nada queda indemne luego del paso de la vista, hasta lo más trivial se transforma bajo el peso de su fuerza analítica y de su escepticismo:

La chica de la caja de Carrefour Express diciendo quién sigue, la mujer que espera en la fila del Carrefour Express mientras mira su teléfono celular y una nena vestida con un pantalón rosa y zapatillas con rueditas le tira la manga, el kiosco donde venden películas con carátulas desvaídas por el sol, la veterinaria donde hay bolsas de alimento para perros cubiertas de polvo, todo lo que siempre estuvo ahí, aumentado por una lente demencial y transformado en una motosierra que trepana el cerebro, es insoportable. (68)

Si bien parece que siguiera los pasos de su admirado George Perec al interrogarse sobre lo trivial y lo fútil para acceder a una nueva comprensión de los hábitos cotidianos, en realidad Guerriero muestra qué acecha en/detrás/con ellos. Sus crónicas enseñan que correr no es solo correr, es sumergirse en una corriente de conciencia que lleva hacia el pasado ("My Derry"); cantar inesperadamente de forma entonada una mañana significa recordar que nunca pudo hacerlo antes y que su madre muerta sí lo hacía ("El rastro"); enumerar en detalle las actividades realizadas en un día -hacer compras, hornear pan, leer, escribir- es descubrir que "no basta" (81) y reflexionar sobre la presión posmoderna para hacer más y mantenerse ocupado. La rutina, la vida en el hogar, las cosas insignificantes son despedazadas en pequeños actos hasta que recuperan sentido.

Este reordenamiento de lo cotidiano tiene como disparador habitual el recuerdo y la evocación; la columnista circula por los corredores de la memoria y tensa los tiempos pasado y presente para intensificar las iluminaciones de sentido:

Nos gustaban los circos. Los circos como este donde estoy ahora, en medio de la pampa, la pampa de pueblo chico donde me crié, la pampa plana, la pampa helada. [...]. Un circo que es y que no es como aquellos a los que íbamos juntos. [...] Nos gustaban los circos. El secreto de los circos ("Imaginate, hijita, la vida de esta gente, de pueblo en pueblo, qué maravilla", me decías, y yo pensaba con terror que un día ibas a irte como esa gente, de pueblo en pueblo, qué maravilla, que ibas a dejarme sola), los circos magníficos, las tres pistas, los trapecistas enlazándose en el vacío como aves enervadas, vos con tu bufanda gris tejida por mamá, tus manos suaves ("Son despreciables, hija, hijita, no son de trabajador. Yo quería manos de albańil, no estas manos", decías, y yo me preguntaba si lo hermoso era hermoso o, como decías, despreciable), y yo arrebujada en mi tapado de terciopelo apretando mi terror o mi risa contra tus solapas. (51) 
Las dos escenas se superponen en la escritura y cruzan los tiempos -la infancia y la adultez- y las identidades - la mujer y la niña-, pero comparten como hilo conductor la interrogación y la incomprensión respecto de los seres más cercanos. El abismo que separa la diferencia de valoraciones introducida por la palabra bivocal de la cita abre el saber hacia zonas desconocidas y sugiere, en medio de una perfecta escena de felicidad filial, la insatisfacción del padre y un mundo de aspiraciones no consumadas. Así, la mujer que rememora no permite que el relato sea solo un extracto de inocente alegría pasada, sino que interviene la narración con el discurso para quebrarlo, para mostrar los riesgos de los recuerdos demasiado monolíticos.

Si la experiencia es "lo que puede ser puesto en relato, algo vivido que no solo se padece sino que se transmite" (Sarlo Tiempo pasado 31), Guerriero apuesta a relatar la suya, pero para estallar el sentido cristalizado de lo cotidiano ${ }^{7}$. De esta forma, a diferencia de la escritura autobiográfica que suele producir un efecto necrológico (Giordano El giro autobiográfico) por la construcción de un relato lineal y coherente sobre el yo, estos textos, con su anclaje en la actualidad y en la intervención temporal, anulan la presentación unívoca de la historia de un sujeto. La memoria no se fosiliza en un gesto nostálgico sino que se convierte en una forma de anudar los tiempos para elaborar experiencia a través de la reflexión.

Esta actitud crítica sobre la recuperación de la experiencia cotidiana y la construcción de la memoria evita que las zonas textuales del recuerdo se deslicen hacia la melancolía o la nostalgia. Al contrario, aunque en "Supongo", "Era la vida", "Antes", "Perder", "Ayer", "La saga”, entre otras columnas, Guerriero nos advierte que el tiempo es inaprensible, que no puede detenerse ni hacerse retroceder-tempus fugit, se escucha como un eco clásico en todas ellas-, también propone como contracara el desarrollo de un "arte de perder" -siguiendo a la poeta Elizabeth Bishop-, una poética de la aceptación consciente de las realidades inapelables: "No es verdad que todo permanezca dentro de nosotros. Hay cosas que se pierden para siempre. Hay, en el coraje de saberlo, una belleza helada. Aunque hunda un dedo en tu corazón y lo rompa en pedazos" (Guerriero Zona de obras 36). Los afectos, los objetos, los momentos, el deseo desaparecerán indefectiblemente; pero en vez del pesimismo barroco, y a pesar del dolor que causa este hecho, la salida es el fortalecimiento del yo, la aquiescencia de la pérdida.

De esta forma, el relato de la desaparición se convierte en el núcleo temático de muchos de los textos, los atraviesa con un escepticismo sereno que da cuenta del "arte" aprendido en el transcurso de una vida:

7 Leonor Arfuch, en su conocido libro sobre las formas biográficas, rastrea el concepto desde Gadamer para afirmar que Erlebnis incluye tanto la experiencia o vivencia como su resultado y designa "la unidad mínima de significado que se hace evidente a la conciencia en reemplazo de la noción kantiana de sensación" (El espacio biográfico 35). No indagaré aquí acerca de las diversas conceptualizaciones sobre la experiencia y los problemas asociados a la capacidad de narrar, tan certeramente trabajados por críticos como Walter Benjamin o Giorgio Agamben, a quienes remito. 
el aroma de mi abuela. El aroma de su casa con vitraux y galería cubierta y pisos de pinotea que ella recorría llevando -llevándome- chocolate con leche y pan con manteca y azúcar. La hermosa casa de mi abuela ya no está, ni va a volver, y mi abuela, con sus ojos de agua, tampoco, porque está muerta. (32)

La muerte asoma en las reflexiones como una presencia ubicua, aunque a veces solapada; se la sugiere, se la nombra, se la narra, se la rodea con relatos sobre la pérdida: la de su madre, la de su abuela, la de otros conocidos apreciados, como Hebe Uhart o Ricardo Piglia. La advertencia inicial se enlaza, por tanto, con otra, memento mori, pero no solo para compartir esa experiencia universal con los lectores, sino también para seńalar un problema angustiante: discurrir por la vida sin notar la fugacidad del tiempo y la muerte como destino final deviene en una condición patológica, una experiencia vital anestesiada y enajenada.

Este es el verdadero centro de angustia existencial de la voz narrativa de las columnas de Guerriero, la nada, la falta de vértigo, la resignación, la monotonía, el hastío: "Nadie nos advierte, pero el infierno vive en nosotros bajo la forma de la indiferencia" (8). Este horror se presenta con diferentes formas en los textos, desde la cordialidad vacía hasta la falta de la capacidad inquisitiva, y su recurrencia isotópica elabora un paisaje de desazón que introduce los infiernos personales que acosan al sujeto:

A veces, cuando camino por la calle y veo caras sumergidas en la indiferencia, en la resignación o el miedo, me digo: cuidado. Porque ¿cómo es que sucede? ¿Cuándo la fruición de la carne empieza a deslizarse, anestesiada, entre las páginas de un libro, los anteojos para la presbicia, el beso de las buenas noches? ¿Cuándo dejamos de reírnos como lobos? ¿En qué momento la prudencia empieza a ser más importante que todo lo demás, el crédito hipotecario que todo lo demás, la compra en el supermercado que todo lo demás? ¿Cómo, en qué momento los domingos de almuerzo con los suegros reemplazan para siempre el desayuno a las cuatro de la tarde, el amasijo, los tiernos bordes de la noche licuándose en un amanecer de pájaros ardientes? (95)

Frente a esta peligrosa deriva, Guerriero propone entrenarse para estar despierta, hacerse preguntas todo el tiempo por lo que pasó y por lo que vendrá, no conformarse, ser consciente, estar en guardia contra estos infiernos que ni el mismo poeta florentino pudo imaginar.

Esto conlleva la aparición en las columnas de una interrogación continua por sus estados mentales, un análisis minucioso de los motivos que la llevan del optimismo tranquilo a la desazón, de la felicidad serena a la irritación. Esta exploración de la subjetividad evita convertirse en una forma de terapia pública: si el dolor personal aparece, no es para exhibirlo buscando la conmiseración de los lectores; si elementos de la vida privada se filtran (su pareja Diego, su amor gastado por su padre, etc.), no intentan ser un espectáculo. El sensacionalismo de lo íntimo o una escritura dominada por el interés de representación narcisista (Sibilia) constituyen terrenos prohibidos, desvíos que buscan obturarse por medio de la introspección crítica. 
Los registros de la intimidad que presentan los textos funcionan, entonces, como pivote que sostiene la reflexión, la pregunta por la relación entre la memoria y la experiencia, y entre la experiencia consciente y el tránsito automático por la vida. Sin duda son preocupaciones de orden general, pero se accede a ellas a partir del recuerdo personal. Esta indagación conforma una violencia sobre sí -recordemos que lo íntimo es tanto penetración como introducción-porque es un ejercicio de inquisición sobre la psiquis que se vive como una apropiación violenta, un "saqueo" $(6)^{8}$ : "metí el hocico en la memoria como un caníbal que se devora a sí mismo" (20). Esta agresión también implica un trabajo de extrañamiento. Si lo íntimo es "algo propio, porque intransferible, pero también impersonal, íntimamente extraño" (Giordano El giro autobiográfico 59), Guerriero debe volverse otra para desarmarse, para devorarse, para mirarse y llegar a ese orden universal sobre el que aspira a reflexionar?.

En este sentido, pese a que es tentador hacer una lectura autobiográfica del libro, buscar las coincidencias referenciales, atribuir directamente a Leila Guerriero ese discurso y pretender conocerla, se debe refrenar esa deriva y recordar el ejercicio de escritura y de rememoración. El que afirme en diferentes medios que lo que se está utilizando como material narrativo de base es la experiencia personal (véase Guerriero "No existe una mirada femenina"; "Quiero que mis columnas") no significa que las columnas sean un acto confesional de mostración de la verdad interior de Guerriero. Recordemos lo que señalaba al respecto Giordano: "Las fabulaciones de sí mismo son performances de autor en las que la subjetividad se construye tanto como se descompone." (El giro autobiográfico 103). Existe una voz narrativa que se dice "soy Leila", que se autofigura como una escritora y periodista, pero a la vez esa misma voz advierte que es una representación de la multiplicidad de preocupaciones sobre la condición humana contemporánea.

Sin detenerme en exceso en este punto, no solo porque no es el objetivo de este trabajo cuestionar la relación entre la firma, el personaje cronista y la biografía pública de Guerriero, sí debo aclarar que, aunque algunos podrían pensar estas columnas como ejercicios de autoficción, considero que no es necesaria esta apropiación teórica ya que aquí no se observa el intento de crear un efecto de ambigüedad, de confesión y fantasía, o de inventarse una personalidad y una

8 Nora Catelli afirma que lo íntimo posee dos acepciones: introducirse un cuerpo por los poros o espacios huecos de una cosa; introducirse en el afecto o ánimo de uno. Así, tiene que ver con actitudes distintas del sujeto o sobre el sujeto, dos maneras de intervención en el ánimo o en el cuerpo propio o de otro: "Gestos vinculados con la penetración (física pero figuradamente también moral o psicológica) de un sujeto sobre sí mismo o sobre otro, y con la introducción (física pero figuradamente también psíquica y moral) de algo en un sujeto; o de un sujeto a otro (en el sentido de presentación)" (46).

9 José Luis Pardo afirma que lo íntimo no es una gradación de lo privado sino una dimensión irrepresentable de la subjetividad, una reserva de indeterminación que escapa a la dialéctica simple en la que lo privado y lo público se oponen para poder complementarse. Por lo tanto, la realización de cualquier performance autobiográfica requiere una distancia sobre sí que transforma el hablar o el escribir en una experiencia de la propia ajenidad. 
existencia (Robin $)^{10}$. Justamente, el trabajo con la memoria, con lo íntimo y lo personal no buscan el fortalecimiento de la identidad ni la solidificación de un sentido sobre el yo que narra. No importa la referencialidad de lo narrado porque lo que se presenta en las columnas podrían ser recuerdos inventados siempre que mantuviesen su carácter auténtico de experiencia humana, su capacidad de interpelar al lector a partir de la coincidencia.

Tal como propuso Beatriz Sarlo (Tiempo pasado), debemos recuperar la desconfianza sobre la inmediatez y sinceridad de la voz en primera persona en el testimonio, en especial cuando es la única fuente ${ }^{11}$. Asimismo, si las escrituras del yo siempre tienen un elemento testimonial marcado, también poseen como contracara la fabulación, la omisión, la transformación de lo recordado. La articulación de los recuerdos en memoria, su recuperación mediando el tiempo y lo discursivo, los límites de la rememoración, su conversión en un relato que le asigna un orden particular, todos son elementos ampliamente estudiados y no constituyen el objeto del presente desarrollo.

La propia Guerriero conoce el elemento ficcional presente en toda escritura del yo y lo explota: sin adscribir de modo explícito a las críticas de la subjetividad y la representación, como las de Paul De Man o Jacques Derrida ${ }^{12}$, juega a ponerse máscaras frente a nuestros ojos (recordemos "El pacto"), se presenta como una subjetividad múltiple, no estable y busca debilitar la lectura referencial. Guerriero no se fabrica intencionalmente como un personaje "ficcional", pero esa presencia de materiales personales está al servicio de la reflexión sobre cuestiones de la experiencia humana y no del desarrollo de un yo; es decir, sin ocluir esta lectura, tampoco se debe desconocer la operatividad ficcional de la elaboración textual.

En esta primera zona textual analizada se observa una tendencia a tensar los límites entre literatura, periodismo y vida ${ }^{13}$. Sin embargo, se busca evitar las lecturas referenciales o autobiográficas en pos de una reflexión sobre ciertas pre-

10 El término fue acuñado por Serge Doubrovsky y desarrollado como concepto teórico por varios críticos; Manuel Alberca, por ejemplo, lo ha definido por el "pacto ambiguo" que lo sostiene: presentarse con plena conciencia del carácter ficcional del yo, pero construir un texto que nos habla de la propia existencia del autor y la propone simultáneamente como ficticia y real.

11 No deseo indagar aquí sobre las críticas que le realizaron a esta propuesta, baste afirmar que no se trata de impugnar el testimonio de las víctimas, sino de señalar que se caracteriza por tener esas zonas de indefinición.

12 Ambos, desde perspectivas propias, impugnan la creencia en la posibilidad de un sujeto estable; su identidad en realidad está sostenida por una ficción de unidad apoyada en el texto que la elabora (De Man) o en la firma (Derrida).

13 Existe una orientación marcada en la crítica contemporánea a relacionar este tipo de problemas con la propuesta de Josefina Ludmer sobre las literaturas posautónomas; elijo no utilizar esta categoría ya que su operatividad teórica ha sido cuestionada en varias oportunidades por críticos como Martín Kohan, Miguel Dalmaroni y Alberto Giordano. No es el objetivo de este artículo desarrollar los argumentos de la polémica, por eso remito a Giordano "Un avatar de las literaturas posautónomas". 
ocupaciones intemporales asociadas a la existencia humana. Negando cualquier tipo de trascendencia de la conciencia, la mirada crítica de Guerriero subraya la importancia de la consciencia cotidiana y la aceptación de la pérdida.

\section{Paisajes sentimentales del presente: resistencia y apropiación}

el discurso amoroso es hoy de una extrema soledad. Es un discurso tal vez hablado por miles de personas (¿quién lo sabe?), pero al que nadie sostiene; está completamente abandonado por los lenguajes circundantes: o ignorado, o despreciado o escarnecido por ellos, separado no solo del poder sino también de sus mecanismos (ciencias, conocimientos, artes).

Roland Barthes, Fragmentos de un discurso amoroso.

Esta cita clásica del maravilloso libro de Roland Barthes nos traslada a un tiempo particular, mediados de los setenta, cuando el universo de los afectos era un espacio poco frecuentado por la crítica y la teoría, momento en el cual ocuparse de estos temas "nimios" garantizaba la mirada peyorativa del campo académico $^{14}$. Mucho ha pasado desde entonces y el discurso amoroso, en parte gracias al giro afectivo, se encuentra hoy en el centro de atención de teorías sociológicas, psicológicas, filosóficas, entre otras.

La proliferación de estos estudios ha traído como una de las consecuencias más evidentes la percepción de un proceso de estandarización de las emociones, que delimita conductas afectivas y axiológicas sanas y enfermas e instaura un ideal comunicacional, el cual afirma la capacidad de comprensión de las emociones y somete los sentimientos a un intenso proceso de racionalización: las emociones deben verbalizarse e intelectualizarse constantemente (Illouz El futuro del alma). Una multiplicidad de discursos y objetos culturales responden al régimen emocional del presente y, como corolario, nuestros imaginarios colectivos se encuentran habitados por escenas e imágenes que expresan estereotipos aceptados de relaciones íntimas y paternofiliales y que muchas veces recuperan la tradición del sentimentalismo.

Frente a este ideal comunicacional y esta estandarización, Guerriero explora en sus columnas zonas no homogeneizadas de la vida emocional y reescribe el paisaje sentimental contemporáneo. El recorrido deconstruye desde las relaciones de pareja hasta los afectos familiares, moviéndose por el límite sutil de un distanciamiento irónico que evita caer en la subestimación o en la arrogancia.

14 Recordemos que este libro nació en las clases del seminario sobre el discurso romántico del amor-pasión que Barthes dictó en École des Hautes Études en Sciences Sociales entre 1974 y 1976. 
Si para salir del infierno del conformismo y la monotonía Guerriero apela a una actitud interrogativa constante, también el paisaje sentimental del presente relacionado a los afectos es deconstruido metódicamente. La columna "Mamita”, por ejemplo, trabaja con los afectos filiales más cercanos para mostrar las sombras dentro del ideal cristalizado por los medios:

Mi madre como mami, te quiero. Mi madre como mami, sos lo más lindo del mundo. Mi madre como feliz día, mami. Mi madre como por favor, mami, basta no me grites más. Mi madre como no ves, tarado, que no servís para nada. Mi madre como mi chiquito, pobre, siempre tan tonto. Mi madre como sos una inútil, te dije que trajeras leche entera, no descremada, ahora vas y la devolvés y no llores porque encima te vas a ligar una cachetada. Mi madre como cállate, mariquita. Mi madre como tengo cosas más importantes que hacer que ocuparme de tus pavadas. Mi madre como sos un fracaso. [...] mi madre como un hijo mío no se mea en la cama. Mi madre como una hija mía no sale así a la calle. [...] Mi madre como soy tu madre y sos mío, mía, de mí, para mí, por mí, mi pequeño juguete de carne, mi insecto, mi mińón, mi pedazo de nada (33-34).

Como en el caso de la intervención del recuerdo con la voz insatisfecha del padre, que señalamos en la sección anterior, aquí también se abre el texto a otros discursos. Recuperar la palabra ajena sirve para componer con ella un discurso que represente una semblanza de orden general, en este caso, de la maternidad; no es su madre a quien describe, sino la figura de todas las madres con su cuota de amor, pero, sobre todo, con su innegable porción de sujeción afectiva y de violencia simbólica.

En este mundo afectivo-sentimental, los adultos nunca son simple signo de cuidado y amor incondicional; despojados de sus máscaras habituales, se presentan como sujetos insatisfechos con sus propias vidas que con facilidad caen en la crueldad gratuita. Así, evocar la infancia, ese territorio tan visitado en las columnas, se convierte en un proceso de identificación y recomposición de la opacidad sentimental y de la violencia discursiva:

recordé cosas: las patadas en los tobillos que nos daba un profesor de educación física para que nos ordenáramos en fila; los alaridos de mi profesora de teoría y solfeo cuando no sabía una escala -“¡Dia-tó-ni-ca! ¡¿ No entendés?!”-; el profesor de natación que empujaba a los que no se atrevían a arrojarse desde el trampolín más alto; mis compañeros de colegio hablando de "los piojosos de la Casa del Nińo", un hogar para chicos carenciados. (30)

La ruptura del modo de representar la infancia como espacio inocente o paraíso perdido no significa la construcción de espacios infernales despojados de afectividad, sino simplemente la no idealización. La asunción de esta ambivalencia afectiva inherente a la experiencia real se explora por medio de otros motivos narrativos - la incapacidad de lidiar con la tragedia ajena, la indiferencia ante el dolor de los otros, etc.- para demostrar que "Lo que más amamos, y lo que más 
nos ama, es, también, lo que mejor nos aniquila." (34) y que "Todos hemos sido, alguna vez, el monstruo de alguien" (98).

Además de estas regiones sentimentalmente ambivalentes, en el libro de Guerriero existe una zona diferenciada construida por las microficciones que se agrupan bajo el rótulo "Instrucciones"; numeradas del uno al dieciocho, allí recurre a escenas estereotipadas de las relaciones de pareja -la crisis en modo "tenemos que hablar", la ruptura en varias modalidades, el desgaste por la convivencia cotidiana, el engaño, la mentira, el fin de la pasión erótica, etc.- para construir una serie de instrucciones "sentimentales":

Vaya hasta la sala de su casa. Déjese caer en un sillón. Él va a llegar poco después. Mire por la ventana, como si intentara que él se diera cuenta de que usted es el pararrayos de la melancolía de todo el universo. Él va a preguntar: “¿Qué pasa?”. Piense: "Que todo lo que me gusta de vos ha desaparecido". Diga: "Nada, ¿por?". Él va a decir: "Estás pensativa". Sienta que la garganta se le cierra como si un puño intentara atravesarle la tráquea. Él va a decir: “¿Querés que vayamos a un bar, al cine?”. Diga: "No tengo ganas". Él va a decir "Como quieras". Sienta ira. Pregúntese por qué él no insiste. Sienta que sus pensamientos se confunden como insectos histéricos. Sienta deseos de beber, de fumar. Pregunte: “¿Compraste algo para la cena?”. Él va a decir: "No, ¿vos?”. Diga: "No". Él va a decir: "No importa. Comamos cualquier cosa”. Diga: "Bueno". Mire cómo él se pone de pie y va hacia la cocina. Sienta que la tristeza es un río barroso del que usted ya no va a salir nunca. Póngase de pie. Camine hacia la cocina. Él va a estar mirando el diario. Sienta que su vida es perfecta -estupendo trabajo, casa impecable-, pero que cualquiera tiene una vida mejor que la suya. Sienta una rabia seca. Piense: "Quiero abrirme un hoyo en la mano". Piense "Él no se daría cuenta”. Quiera sangrar profusamente. Diga “¿Querés vino?”. Escuche cómo él dice: "No, gracias". Abra un cajón y, al cerrarlo, empújelo con fuerza excesiva. Vea cómo él levanta la cabeza. Diga con furia, como si fuera un canto guerrero: "Yo sî". Abra una botella. Escuche cómo él dice: "Amor, no te preocupes. Todo va a estar bien”. Sienta que los ojos le queman. Pregúntese: “¿Esto que siento es odio?”. Sienta que es necesario decir algo. Guarde silencio. Piense: "¿Esto que siento es desprecio?". Empiece a cocinar. La semiótica de esos cuerpos nos habla de la incomprensión, de la imposibilidad. (99-100)

El procedimiento, heredero del método dramático barthesiano, se sostiene sobre la reconstrucción de escenas tradicionales de la convivencia y del amor romántico, pero bajo la luz del agotamiento ${ }^{15}$. La performance amorosa que realizan los protagonistas de cada escena dramática es descripta analíticamente por un narrador omnisciente, quien recupera la perspectiva interior de uno de los

15 En Fragmentos, Barthes explicaba su procedimiento: "Todo partió de este principio: no se debía reducir lo amoroso a un simple sujeto sintomático, sino más bien hacer entender lo que hay en su voz de inactual, es decir, de intratable. De ahí la elección de un método "dramático", que renuncia a los ejemplos y descansa sobre la sola acción de un lenguaje primero (y no de un metalenguaje). Se ha sustituido pues la descripción del discurso amoroso por su simulación, y se ha restituido a este discurso su persona fundamental, que es el yo, de manera de poner en escena una enunciación, no un análisis.” (17). 
involucrados y, al confrontarla con su conducta visible, produce una distancia irónica que hace estallar la interacción de las parejas.

Asimismo, como en las columnas sentimentales del pasado, la voz narrativa asume el lugar del saber y explica los "secretos" de la relación sentimental, pero en vez de orientar hacia el éxito, garantiza el fracaso amoroso. El montaje interior-exterior corroe y deforma el registro cursi y estereotipado que era propio de ese tipo de columnas ${ }^{16}$. Si antes la pregunta era por el amor romántico - ¿cómo conseguirlo? ¿cómo conservarlo?-, ahora es por la capacidad de relacionarse con el otro y la imposibilidad de no herirlo.

Guerriero trabaja en y contra una tradición escrituraria sentimental: esa literatura que diseñaba un elaborado código del amor -miradas, gestos y roces en su versión más naif (Sarlo El imperio de los sentimientos), exploración erótica directa en la versión más actual- es contrarrestada por el lenguaje propio que elaboran las instrucciones de Guerriero. De esta forma, los gestos (la pose taciturna, golpear el cajón, etc.) serán exhibición de la desesperación solapada y la mirada, mecanismo de abstracción para reinterpretar a aquel con el que se convive. Como en la cita previa, los gestos de la vida cotidiana se recodifican en clave de fracaso y conllevan reconocer el fin del enamoramiento, esa etapa inicial en la cual todo parece perfecto, y el predominio de la insatisfacción ${ }^{17}$. La semiótica de esos cuerpos nos habla, por tanto, de la incomprensión propia y respecto de los otros, y de la imposibilidad de comunicar (verbalizar) los sentimientos.

También se recupera en las "Instrucciones" cierto capitalismo cognitivo el cual, como mencionábamos antes, convierte a los afectos en mercancías de consumo y estandariza modos de relacionarse, desde qué tipo de actividades se comparten (véase la "Instrucción" sobre las salidas en pareja), hasta cómo "administrar" las separaciones ${ }^{18}$ :

16 Si bien coincidimos en que hay que evitar las "lecturas condescendientes" sobre este tipo de literatura, como las columnas sentimentales, es indudable que los "textos de la felicidad" (Sarlo El imperio de los sentimientos 10-11) diseñaron por décadas un extenso imperio de sentimientos, en el cual los deseos, la moral y los requisitos sociales asociados a la familia y al matrimonio delineaba un régimen afectivo-sentimental homogéneo y hegemónico controvertible.

17 Un trabajo similar había realizado Gilles Deleuze para identificar los "signos del amor" en los libros de Marcel Proust, signos engañosos que conllevan el sufrimiento del enamorado: "los signos del amor son a su vez pesares, ya que siempre implican una mentira del amado, como una ambigüedad fundamental de la que nuestros celos se benefician y alimentan" (86-87). Si en ellos, enamorarse era aprender a decodificar los signos que el sujeto de deseo emitía, desenamorarse suponía un camino similar: aprender la verdadera imagen del otro.

18 Illouz afirma que la nueva etapa del capitalismo tardío se caracteriza por el carácter difuso de los límites entre realidad y ficción en lo que respecta a las relaciones sentimentales. Las formas de vivir el romance estarían determinadas por estructuras narrativas preconfiguradas, inscritas en la cultura de los medios de masas, que indican qué actividades recreativas y consumos son adecuados a la utopía de diversión, belleza, intensidad y sensualidad amatoria (El Consumo de la utopía romántica). 
Dígale adiós en un aeropuerto (o en una estación de tren, o de autobuses). [...] Piense: "Si esto fuera una película, yo debería correr hacia ella y ella debería estar corriendo hacia mí". Siga caminando; esto no es una película y usted no tiene tiempo que perder: debe empezar a sufrir. Sufra. Diga: "Hola, aquí está el dolor". Diga: "Hola, bienvenido dolor". [...] "Pregúntese si pensará en usted. Pregúntese cuándo va a volver a verla. Pregúntese si volverá a verla. Suba al auto. Ponga el auto en marcha. Salga del estacionamiento. Respire. Mírese en el espejo retrovisor. No se reconozca. Piense: "Ese no soy yo". Diga en voz alta: "Te necesito". Diga en voz alta: "Te extraño”. Maldígase. Sienta que nada tiene sentido y que no lo tendrá por mucho tiempo. Piense en morir. Elija no morir. Siga adelante. (105-106)

La economía afectiva del capitalismo y su proclividad a entender las emociones como entidades autónomas "gestionables" (Illouz El Consumo de la utopía romántica; El futuro del alma) está presente en los textos de Guerriero; sin embargo, retoma ese lenguaje para tensarlo y mostrar su absurdo.

Los protagonistas de estas microficciones no son solo figuras femeninas que descubren la verdad detrás de la ilusión romántica, sino sujetos en general que llegan al mismo estado de hastío - mujeres que descubren con horror que se están convirtiendo en sus madres, esposos agotados por la incapacidad de satisfacer al otro, cónyuges que se convierten en desconocidos- o que son transformados irremediablemente por el paso del tiempo y la negociación continua con el otro:

Sienta que todo es deforme y falso, un cuento que ella se cuenta a sí misma porque nunca dejará de buscar en usted al héroe que jamás fue, o que fue antes, o que fingió ser cuando ella era alguien a quien usted codiciaba. Sienta una repulsión demente. No por ella, sino por lo que han hecho: por lo que se han hecho. (Teoría de la gravedad 118)

Mientras en los relatos sentimentales tradicionales el fracaso de las relaciones conducía a la caída o a la muerte (Sarlo El imperio de los sentimientos), la ruptura de estas parejas solo conlleva la soledad y la incomprensión. A diferencia del conformismo usual, las microficciones de Guerriero exhiben la resistencia a un orden de deseos caduco -ideal romántico, promesa mediática de pasión y felicidad eterna-, ya que coarta a los sujetos de tal forma que solo es posible el fracaso o, desde una perspectiva más optimista, la felicidad fugaz y momentánea.

No hay maniqueísmo moral o ideológico en los textos, o una mirada peyorativa sobre esos ideales caducos, sino simple escepticismo respecto de la posibilidad de la felicidad duradera: "Un día [él] le dice, por primera vez, "Te amo". Sienta que un anzuelo tira desde el exacto lugar donde tiene el corazón. Sonría, cierre los ojos. Sepa que no hay nada más allá de eso que acaba de obtener. En breve empezará el hastío" (130). Esta reconfiguración del paisaje sentimental se presenta así como una operación política, no porque pregone una militancia en el sentido tradicional, sino porque interpela las zonas seguras de lo social, como el amor filial y el romántico. 


\section{Una poética periodística}

desprecio las versiones planas del mundo - malos contra buenos, víctimas contra victimarios-, y allí donde otro periodismo golpea la mesa con un puño y dice "qué barbaridad", el periodismo en el que creo toma el riesgo de la duda, pinta matices, dice no hay malo sin bueno, dice, no hay bueno sin malo. Allí donde otros hablan de la terrible tragedia y del penoso hecho, el periodismo en el que creo nos susurra dos palabras, pero dos palabras que nos hunden el corazón, que nos dejan helados y que, sobre todo, nos despiertan.

Leila Guerriero, "Dejar morir”, Zona de obras.

Despertar a los lectores, conmoverlos por medio de la presentación de un mundo de claroscuros: Teoría de la gravedad lleva esta premisa escrituraria hasta el límite. Una colección de ensayos en forma de columnas o un conjunto de microficciones que bordean lo íntimo, lo personal y lo sentimental, el libro de Guerriero propone una reflexión aporística sobre la experiencia humana.

La periodista presenta una teoría de la escritura que se basa en "saquear" o "canibalizar" la propia vida pero, evitando las derivas confesionales o terapéuticas y ocluyendo la lectura referencial; recoge esos materiales narrativos para ponerlos a dialogar con ciertos discursos y representaciones sociales que regulan nuestras prácticas y conductas personales siempre en relación con los otros.

Ya sea por medio de la evocación o de la ficcionalización de escenas, cada texto se conjuga para presentar una perspectiva personal, una poética periodística que busca salir de los espacios habituales de la tragedia o lo marginal e indagar sobre otras zonas de la existencia, como el recuerdo, la identidad, los afectos, el amor, la pérdida, el tiempo y la muerte. Los territorios afectivos y los eventos cotidianos que elige analizar deconstruyen imaginarios e interdicciones, así como también el lugar común; nos interpelan por el trabajo de extrañamiento que realiza una voz narrativa impiadosa.

\section{Referencias bibliográficas}

Alberca, Manuel. "Las novelas del yo". La autoficción: reflexiones teóricas, compilado por Ana Casas, Madrid, Arco/Libros, 2012, pp. 123-149.

Angulo Egea, María. "Prefacio. Mirar y contar la realidad desde el periodismo narrativo". Crónica y mirada. Aproximaciones al periodismo narrativo. Madrid, Libros del K.O., 2014, pp. 7-36. 
Arfuch, Leonor. El espacio biográfico: dilemas de la subjetividad contemporánea. Buenos Aires, Fondo de Cultura Económica, 2002.

Arfuch, Leonor. "El 'giro afectivo'. Emociones, subjetividad y política”. DeSignis: Publicación de la Federación Latinoamericana de Semiótica (FELS), vol. 24, junio de 2016, pp. 245-254.

Barthes, Roland. Fragmentos de un discurso amoroso. Traducido por Eduardo Molina. Buenos Aires, Siglo Veintiuno, 2018.

Bernabé, Mónica. Por otro lado. Ensayos en el límite de la literatura. México, Fondo Editorial Estado de México, 2017.

Bonano, Mariana. "Las crónicas de Leila Guerriero y las modulaciones de la voz. Mirada, subjetividad y autoficción”. Perifrasis, 2020, pp. 100-11, https://doi. org/10.25025/perifrasis202011.22.06.

Catelli, Nora. En la era de la intimidad, seguido de El espacio autobiográfico. Rosario, Beatriz Viterbo Editora, 2007.

Deleuze, Gilles. Proust y los signos. Traducido por Francisco Monge. Barcelona, Editorial Anagrama, 1972.

Giordano, Alberto. El giro autobiográfico. Rosario, Beatriz Viterbo Editora, 2020.

Giordano, Alberto. "Un avatar de las literaturas posautónomas. El caso Luz Maruz". El pensamiento de la crítica, Rosario, Beatriz Viterbo, 2015. Epub.

Gorodischer, Julián. "Prólogo". Los atrevidos. Crónicas intimas de la Argentina. Buenos Aires, Marea, 2018, pp. 9-24.

Guerriero, Leila. "Aquí estaré. El Pais, 7 de enero de 2014, https://elpais.com/ elpais/2014/01/07/opinion/1389091037_387525.html.

Guerriero, Leila. "No existe una "mirada femenina" en la literatura, eso es aterrador y machista". Entrevista por Lorena G. Maldonado, El Español, 21 de noviembre de 2019, https://www.elespanol.com/cultura/20191121/leilaguerriero-no-femenina-literatura-aterrador-machista/445706431_0.html.

Guerriero, Leila. "Quiero que mis columnas le hagan sentir al lector menos loco o menos solo". Entrevista por Angélica Tanarro, El norte de Castilla, 16 de noviembre de 2019, https://blogs.elnortedecastilla.es/ angelicatanarro/2019/11/21/quiero-que-mis-columnas-le-hagan-sentir-allector-menos-loco-o-menos-solo/.

Guerriero, Leila. Teoría de la gravedad. Barcelona, Libros del Asteroide, 2019.

Guerriero, Leila. Zona de Obras. Barcelona, Anagrama, 2016.

Illouz, Eva. El Consumo de la utopía romántica: el amor y las contradicciones culturales del capitalismo. Traducido por María Victoria Rodil. Buenos Aires, Katz, 2010. 
Illouz, Eva. El futuro del alma. La creación de estándares emocionales. Buenos Aires, Katz/Centro de Cultura Contemporánea de Barcelona, 2014.

Link, Daniel. "El giro intimista”. Linkillo (cosas mías), 4 de agosto de 2007, http://linkillo.blogspot.com/2007/08/la-imaginacin-intimista.html.

Ludmer, Josefina. "Literaturas postautónomas". Ciberletras. Revista de Critica Literaria y de Cultura, vol. 17, 2007, http://www.lehman.cuny.edu/ciberletras/ v17/ludmer.htm.

Pardo, José Luis. La intimidad. Valencia, Pre-Textos, 1996.

Robin, Régine. "La autoficción. El sujeto siempre en falta". Identidades, sujetos y subjetividades, compilado por Leonor Arfuch, Buenos Aires, Prometeo Libros, 2005, pp. 45-58.

Sarlo, Beatriz. El imperio de los sentimientos. Narraciones de circulación periódica en la Argentina (1917-1927). Buenos Aires, Catálogos Editora, 1985.

Sarlo, Beatriz. Signos de pasión: claves de la novela sentimental del Siglo de las Luces a nuestros días. Buenos Aires, Editorial Biblos, 2012.

Sarlo, Beatriz. Tiempo pasado. Cultura de la memoria y giro subjetivo. Una discusión. Buenos Aires, Siglo XXI, 2005.

Sibilia, Paula. La intimidad como espectáculo. Buenos Aires, Fondo de Cultura Económica, 2013. 